\title{
Optimal carry trade portfolio choice under regime shifts
}

\author{
Chih-Nan Chen ${ }^{1} \cdot$ Chien-Hsiu Lin ${ }^{2}$
}

Accepted: 4 February 2022 / Published online: 7 March 2022

(c) The Author(s), under exclusive licence to Springer Science+Business Media, LLC, part of Springer Nature 2022

\begin{abstract}
This paper studies optimal currency allocation of the carry trade in foreign exchange (FX). A number of empirical studies have documented a phenomenon referred to as the 'forward premium puzzle', which states that the carry trade is profitable on average. However, the carry reversal during the 2008 global crisis periods wiped out the profits earned by the trade. To account for the regime shifts in the joint distribution of returns on the carry trade with FX market portfolios, we adopt a Markov regime switching model. We find evidence of two economic regimes: one state captures periods of the forward premium puzzle and UIP being violated, whilst the other reports high FX volatility and negative return of carry trade portfolio. Furthermore, to quantify the economic significance of regimes in returns on currency portfolios, we consider their importance in investors' optimal portfolio allocation problem. We find strong evidence that optimal currency portfolio holdings vary significantly across regimes and across short and long investment horizons, as investors anticipate a shift out of the current state. Our results also show that the regimes partially anticipate peso events as well as the changes of funding liquidity measured by the TED spreads. A strategy that accounts for regimes, thus, generates overall stronger performance than the single-state Gaussian IID model, a carry trade procedure as well as a buy-and-hold strategy.
\end{abstract}

Keywords Forward premium puzzle $\cdot$ Carry trade $\cdot$ Markov regime switching model · Asset allocation problem

JEL Classification F31 $\cdot \mathrm{G} 11 \cdot \mathrm{C} 58$

\section{Introduction}

In this paper, we investigate an optimal currency allocation problem of the carry trade in foreign exchange (FX). Carry trade refers to a strategy where investors borrow low-yielding currencies and lend high-yielding ones. By engaging in this strategy, the carry trader earns an average positive excess return, which violates the prediction of the uncovered

Chien-Hsiu Lin

clin@mail2.nccu.tw

1 Department of Economics, National Taipei University, Taipei, Taiwan, R.O.C.

2 Department of Money and Banking, National Chengchi University, Taipei, Taiwan, R.O.C. 
interest rate parity (UIP) condition. According to this condition, in a world with risk-neutral and rational investors, the profits gained from differential interest rates across countries will be wiped out by the losses due to the appreciation of the funding currencies. However, a number of empirical studies have documented that most of the time exchange rates do not adjust to offset the extra yield of the investment currencies, a phenomenon referred to as the 'forward premium puzzle', thus resulting in the carry trade being profitable on average (Bilson 1981; Hansen and Hodrick 1980).

The carry reversal during the 2008 global crisis and the COVID-19 pandemic periods motivated us to focus on how the returns on a carry trade portfolio vary over time. Past literature has indicated that high profitability of carry trade depends upon market states, such as market volatility and liquidity. Moreover, the most widely used state variable is FX market volatility. For example, Christiansen et al. (2012) adopt a smooth transition regression model with factor betas governed by FX volatility, and find that carry trades have high exposure to stock markets when FX volatility is high. Copeland and Lu (2016) show that most profits of carry trade can be attributed to low FX volatility periods. Hence, they propose an enhanced trading strategy, which involves adopting carry trades during low FX volatility periods and real exchange rate deviation during high ones.

Carry trade returns are also related to the U.S. dollar value. Past literature has shown that the currency can be regarded as a safe haven due to its property of retaining or appreciating in value during market turmoil. Regarding which, Doroodian and Caporale (2000) find that the U.S. dollar value was positively correlated with uncertainty in the FX markets from 1973 to 1996. Beck and Rahbari (2011) show that the U.S. dollar acts as a safe-haven currency and tends to appreciate during global or local market turmoil in which investors transfer capital to mature markets. Wu and Wu (2017) investigate the asymmetric dependence between the carry trade and U.S. dollar returns, eliciting that the U.S. dollar becomes a safe haven and provides protection for carry trade investors to avoid a crash risk during periods of financial crisis. However, Bazan-Palomino and Winkelried (2021) have shown that during the COVID-19 pandemic, on average, all their sample currencies appreciated relative to the U.S. dollar from March to August 2020. The main source of downward pressure on the U.S. dollar can be attributed to the fact that the Federal Reserve System was creating a massive amount of dollars at an unprecedented rate. To gain clear understanding of the variation of carry trade returns, we adopt a Markov regime switching model in this paper for the joint distribution of returns on a portfolio that borrows in the U.S. dollar and invests in the foreign money market $(D O L)$, with a carry trade portfolio that borrows in the money markets of low yielding currencies and invests in high yielding ones $\left(H M L_{F X}\right)$, as introduced by Lustig et al. (2011).

Since 1989, when Hamilton (1989) adopted the regime-switching model (RSM) to describe business cycles in the U.S., there has been a surge of empirical research and ongoing extension of the model. Due to the RSM being able to match the propensity of financial markets often to change their behavior abruptly and the new behavior of financial variables usually persisting for a significant time period after such a change, the RSMs form an important class of financial time series models. A key feature of the RSM is that its parameters are functions of a hidden Markov chain, the states of which represent hidden states of an economy, or different stages of business cycles. Engel and Hamilton (1990) and Engel (1994) investigate quarterly changes in exchange rates and found RSMs to be good approximations to the underlying processes. Other studies that have employed the RSM for exchange rates, include: Kirikos (2000), Caporale and Spagnolo (2004), Bergman and Hansson (2005), Ismail and Isa (2007) and Ichiue and Koyama (2011). In contrast to past studies, which focus on analyzing a single portfolio 
or exchange rate series, our research employs the RSM to the joint distribution of Dollar and carry trade portfolios. We, hence, contribute to the literature by proposing an enhanced trading strategy, which can allocate optimal weights across foreign exchange portfolios based on regime switching signals.

We find evidence of two economic regimes that capture important time-variations in mean returns, volatilities and return correlations. One state captures periods of low FX volatility and high returns of the $H M L_{F X}$. Carry trade is mostly executed in times of global financial and exchange rate stability, because lower volatility results in lower margins, which enables speculators to take more carry-trade positions. Owing to the huge amount of carry trade execution, low-interest-rate currencies tend to depreciate, thus inducing higher returns on the carry trade portfolio. The other regime captures the periods of high FX volatility and negative return of the $H M L_{F X}$. In addition, there exists a positive correlation between the $D O L$ and the $H M L_{F X}$. Because of high volatility and negative return of the $H M L_{F X}$, many investors turn away from commonly practiced carry-trade strategies, seeking a "safe-haven" in these uncertain times. This results in low-interest-rate currencies appreciating rapidly, thereby offsetting the profits gained from the differentials in interest rates from the carry trade portfolio. Moreover, the traditionally regarded safe-haven currency, the U.S. dollar, also appreciates during a high FX volatility state, causing a positive correlation between the $D O L$ and $H M L_{F X}$. We also show that our regimes are related to major currency crisis events, and that the TED spreads are capable of predicting the regime change through the time-varying transition probabilities.

To quantify the economic significance of these regimes in returns on currency portfolios, we consider their importance in investors' optimal portfolio allocation problem. While there is extensive literature on statistically evaluating the performance of volatility and correlation models (West et al. 1993; Fleming et al. 2001, 2003), there has been little work undertaken formally assessing the economic value of volatility and correlation timing. This motivates our asset allocation approach, which focuses on the presence of predictability linked to regimes underlying the joint distribution of returns on the DOL and $H M L_{F X}$ portfolios. The economic value of investment strategies in the carry trade portfolio is, of course, related to the average returns and further depends on how much these vary across economic states. For a long-horizon investor, an important issue is whether carry trade benefits can be expected to persist in the future. In this paper, we extend the Monte Carlo methods in Barberis (2000), and Detemple et al. (2003) to characterize investors' optimal portfolio weights under imperfect information about the current state. We find strong evidence that optimal currency portfolio holdings vary significantly across regimes, particularly for the short-term market timing effects. In the long-run, optimal portfolio weights converge across regimes due to uncertainty about future market states. In addition, rebalancing opportunities make investors respond more aggressively to the current state, because they can simply adjust the portfolio weight, if the perceived state probabilities change during the next period. Our out-of-sample testing also shows that, compared to the single-state Gaussian IID model, the two-state one generates high mean returns, but tends to be more volatile. Moreover, our two-state model is shown partially to anticipate peso events as well as the changes in funding liquidity measured by the TED spreads, thereby providing overall stronger performance than the single-state Gaussian IID model, a carry trade procedure as well as a buy-and-hold strategy.

The remainder of the paper is organized as follows. Section 2 addresses the regime-switching model for the joint return process, whilst Sect. 3 briefly introduces the data and currency portfolio returns as well as presenting the empirical results of the regime-switching model. Section 4 sets up the asset allocation problem and Sect. 5 reports empirical asset allocation 
results. Section 6 evaluates the out of sample performance of the competing models, with Sect. 7 containing the conclusion to the paper.

\section{Regime-switching model in the joint return process}

The basic idea of the RSM is that the model assigns probabilities to the occurrence of different regimes, which have to be inferred from the data. The nonlinearity feature of the financial time series that can occur in two or more regimes has motivated the use of RSMs. We model the joint distribution of a vector of $n$ portfolio returns, $r_{t}=\left[r_{1 t}, r_{2 t}, \ldots r_{n t}\right]^{\prime}$, as a multivariate regime-switching process driven by a common discrete state variable $s_{t}$ that takes integer values between 1 and $k$ :

$$
r_{t}=\mu_{s_{t}}+\varepsilon_{t}
$$

where $\mu_{s_{t}}=\left[\mu_{1 s_{t}} \ldots \mu_{n s_{t}}\right]^{\prime}$ is a vector of mean returns in state $s_{t}$, and $\varepsilon_{t}=\left[\varepsilon_{1 t} \ldots \varepsilon_{n t}\right]^{\prime} \sim N\left(0, \sum_{s_{t}}\right)$ is the vector of return innovations that are assumed to be joint normally distributed with zero mean and a state-specific covariance matrix $\sum_{s_{t}}$. Our assumption about the innovations to returns is, thus, capable of capturing time-varying volatilities and correlations in the joint distribution of asset returns (Timmermann 2000; Manganelli 2004; Patton 2004). Each state is the realization of a first order Markov chain governed by the $k \times k$ transition probability matrix $P$, with element $p_{j i}$, defined as:

$$
\operatorname{Pr}\left(s_{t}=i \mid s_{t-1}=j\right)=p_{j i}, i, j=1, \ldots, k .
$$

The model (1-2) nests several popular models from the finance literature as special cases. In the case of a single asset and two states, $n=1, k=2$, according to Engel and Hamilton (1990), the model can describe a variety of processes depending on the values taken by the six parameters $\mu_{1}, \mu_{2}, \sigma_{1}, \sigma_{2}, p_{11}$ and $p_{22}$. State 1 and state 2 represent currency depreciation and appreciation, respectively. When in the depreciation state, the mean value is $\mu_{1}$, and the volatility is $\sigma_{1}$, whereas in state 2 , the appreciation state, the mean value is $\mu_{2}$, and the volatility is $\sigma_{2}$. The transition probability of appreciation-depreciation cycles can be defined by $P$. Most importantly from Engel and Hamilton's perspective, is the ability of this model to capture so-called long swings in the exchange rate, which are characterized by opposite signs for $\mu_{1}$ and $\mu_{2}$ as well as large values of $p_{11}$ and $p_{22}$. Supposing that the exchange rate is in state 1 and that $\mu_{1}$ is positive, under the long swings hypothesis, it is expected to remain in that state for $1 /\left(1-p_{11}\right)$ periods and increase by $\mu_{1}$ in each. Once it switches to state 2 , the exchange rate is expected to remain there for $1 /\left(1-p_{22}\right)$ periods and to fall by $\mu_{2}$, on average, in each. Clearly this process has parallels with the desires of chartists to identify long-lived periods of currency appreciation or depreciation.

\subsection{Regime-switching model with time-varying transition probabilities (TVTP)}

To model the time-varying transition probabilities, we assume the transition probabilities $\operatorname{Pr}\left(s_{t}=i \mid s_{t-1}=j\right)$ are governed by a function of several macroeconomic variables.

$$
\operatorname{Pr}\left(s_{t}=i \mid s_{t-1}=j\right)=p_{t}^{j i}\left(z_{t-1}\right)
$$


where $P_{t}^{j i}(\cdot)$ is a function of a $k \times 1$ vector of the observed exogenous or predetermined variables $z_{t-1}$ and $\sum_{i} P_{t}^{j i}(\cdot)=1 \forall j, i \in\{1, \ldots, k\}$. The transition probabilities are further assumed to be evolving as a probit function of $z_{t-1}$. Specifically, in the case of the two states, the transition probability matrix is given as:

$$
P_{t} \equiv\left[\begin{array}{ll}
p_{t}^{11} & p_{t}^{12} \\
p_{t}^{21} & p_{t}^{22}
\end{array}\right]
$$

with

$$
\begin{aligned}
& p_{t}^{11}=\Phi\left(a \cdot z_{t-1}^{\prime}\right), p_{t}^{12}=1-\Phi\left(a \cdot z_{t-1}^{\prime}\right) \\
& p_{t}^{21}=\Phi\left(b \cdot z_{t-1}^{\prime}\right), p_{t}^{22}=1-\Phi\left(b \cdot z_{t-1}^{\prime}\right)
\end{aligned}
$$

where $\Phi$ is the cumulative standard normal density function, as illustrated in Ding (2012).

Diebold et al. (1994) provide a tractable methodology to derive the maximum likelihood estimation based on an EM algorithm. They demonstrated that their extension to Hamilton's Markov switching model by allowing for time-varying transition probabilities not only nests the framework with fixed transition probabilities, but also, better describes the true data generating process through simulation.

\section{Regimes in foreign money markets and carry trade returns}

This section describes the data on exchange rates and the construction of the currency portfolios as well as presenting the regimes in the joint return process of these portfolios.

\subsection{Data}

As the aim was to apply an RSM in the paper for the joint distribution of returns on the $D O L$ and $H M L_{F X}$, as introduced by Lustig et al. (2011), we collect the data of currency portfolios summarized by these authors from November 1983 to May 2021 . $^{1}$ The main data set contains, at most, the 35 different currencies of: Australia, Austria, Belgium, Canada, Hong Kong, the Czech Republic, Denmark, the Euro area, Finland, France, Germany, Greece, Hungary, India, Indonesia, Ireland, Italy, Japan, Kuwait, Malaysia, Mexico, the Netherlands, New Zealand, Norway, the Philippines, Poland, Portugal, Saudi Arabia, Singapore, South Africa, South Korea, Spain, Sweden, Switzerland, Taiwan, Thailand and the United Kingdom. They sort currencies into six portfolios and rebalance them at the end of each month, according to their forward discount. The first portfolio contains the funding currencies of a carry trade strategy (lowest forward discount or interest rate differential), while the last contains the investment currencies in a carry trade strategy (highest forward discount or interest rate differential). Next, they compute the excess return for each portfolio as an equally weighted average of the currency excess return ${ }^{2}$ within that portfolio. For

\footnotetext{
1 The data for the currency portfolios can be downloaded from Adrien Verdelhan's website, http://web.mit. edu/adrienv/www/Data.html.

2 The $\log$ currency excess return can be stated as the log forward discount minus the log spot rate in the next period.
} 
Table 1 Descriptive statistics

\begin{tabular}{lcccccccc}
\hline Portfolios & 1 & 2 & 3 & 4 & 5 & 6 & DOL & $H M L_{F X}$ \\
\hline Mean (\%) & -0.64 & -1.18 & 0.08 & 1.13 & 1.91 & 2.95 & 0.71 & 3.59 \\
Median (\%) & -1.45 & -0.21 & -0.74 & 0.13 & 1.63 & 4.56 & 1.25 & 4.87 \\
Std. Dev. (\%) & 2.21 & 2.03 & 2.05 & 2.13 & 2.32 & 2.71 & 1.92 & 2.47 \\
Skewness & 0.29 & 0.05 & 0.05 & -0.08 & -0.44 & -0.39 & -0.23 & -0.63 \\
Kurtosis & 1.42 & 1.43 & 1.20 & 2.36 & 2.40 & 1.65 & 0.76 & 1.47 \\
AR(1) & -0.0020 & 0.0556 & -0.0049 & 0.0676 & 0.1011 & 0.0942 & 0.0578 & 0.0966 \\
SR & -0.29 & -0.58 & 0.04 & 0.53 & 0.82 & 1.09 & 0.37 & 1.45 \\
SO & -0.41 & -0.80 & 0.05 & 0.77 & 1.17 & 1.57 & 0.52 & 2.07 \\
Std. Dev. (-) (\%) & 1.54 & 1.48 & 1.44 & 1.45 & 1.63 & 1.88 & 1.36 & 1.73 \\
\hline
\end{tabular}

This table presents descriptive statistics of currency excess returns realized at time $t$ by sorting currencies into six groups at time $t-1$ using one-month forward discount. The first portfolio contains currencies with the lowest forward discount (low interest rate), while the last has the highest (high interest). $D O L$ is the average excess return across portfolios. $H M L F_{F X}$ is a long-short portfolio that is long in portfolio 6 and short in portfolio 1 . Thetable reports discrete excess returns adjusted for transaction costs. The mean, median and standard deviations are annualized. The table also reports the first order autocorrelation coefficient $\mathrm{AR}(1)$, the annualized Sharpe ratio (SR) and the annualized Sortino ratio (SO)

the purpose of accounting for transaction costs in portfolio returns, they also assume that investors go short on foreign currencies in portfolio 1 and long on those in the rest of the portfolios. $^{3}$

Table 1 presents summary statistics for the six currency portfolios, where we report currency excess returns net of transaction costs. We construct $D O L$ and $H M L_{F X}$, as in Lustig et al. (2011), with the former denoting the average excess return on the six currency portfolios and thus, implying an equally weighted strategy across all portfolios. The average excess return on all currency portfolios is simply the outcome of a strategy that borrows in the US money market and invests in the foreign ones. This portfolio is driven by the fluctuations of the US dollar against a broad range of currencies and is defined as the dollar risk factor, $D O L . H M L_{F X}$ denotes a long-short strategy that is long in portfolio 6 and short in portfolio 1 . This is equivalent to the carry trade strategy that borrows in the money markets of low yielding currencies and invests in those of high yielding ones. The high minus low portfolio is called the slope factor, and is defined as $H M L_{F X}$. All figures in Table 1 are annualized and reported in US dollars.

The average excess returns display a monotonically increasing pattern when moving from portfolio 1 to portfolio 6 . The annualized average excess return on portfolio 1 is about $-0.64 \%$ per annum, and $2.95 \%$ per annum on portfolio 6 . The average excess return from holding a DOL portfolio is about $0.71 \%$ per annum, thus suggesting that a US investor would demand a positive risk premium for holding foreign currency while borrowing in the US money market. The average excess return from an $H M L_{F X}$ portfolio is around $3.59 \%$ per annum. Skewness ranges from 0.29 (portfolio 1) to $-0.63\left(H M L_{F X}\right)$, which is consistent with the findings of

\footnotetext{
3 As we have bid-ask quotes for spot and forward contracts, we can compute the excess return net of transaction costs. The net log currency excess return for an investor who goes long in a foreign currency is the bid price of the log forward discount minus the ask price of the log spot rate in the next period, whereas the net log currency excess return for one who goes short in a foreign currency is the bid price of the log spot rate in the next period minus the ask price of the log forward discount.
} 
Table 2 Parameter estimates of the regime-switching model for $D O L$ and $H M L_{F X}$ returns with constant transition probabilities

\begin{tabular}{|c|c|c|}
\hline & $D O L$ portfolio & $H M L_{F X}$ portfolio \\
\hline \multicolumn{3}{|l|}{ Panel A: Single-state model } \\
\hline 1. Mean excess return & $0.0006(0.0009)$ & $0.0030(0.0012)^{* *}$ \\
\hline \multicolumn{3}{|l|}{ 2. Correlations/Volatilities } \\
\hline$D O L$ portfolio & $0.0192 * * *$ & \\
\hline$H M L_{F X}$ portfolio & $0.1273 * * *$ & $0.0247 * * *$ \\
\hline \multicolumn{3}{|l|}{ Panel B: Two-state model } \\
\hline \multicolumn{3}{|l|}{ 1. Mean excess return } \\
\hline Regime 1 & $0.0011(0.0010)$ & $0.0072(0.0013)^{* * * *}$ \\
\hline Regime 2 & $0.0018(0.0025)$ & $-0.0046(0.0037)$ \\
\hline \multicolumn{3}{|l|}{ 2. Correlations/Volatilities } \\
\hline \multicolumn{3}{|l|}{ Regime 1} \\
\hline$D O L$ portfolio & $0.0140 * * *$ & \\
\hline$H M L_{F X}$ portfolio & -0.0296 & $0.0175 * * *$ \\
\hline \multicolumn{3}{|l|}{ Regime 2} \\
\hline$D O L$ portfolio & $0.0265 * * *$ & \\
\hline$H M L_{F X}$ portfolio & $0.1870^{* *}$ & $0.0331 * * *$ \\
\hline 3. Transition probabilities & Regime 1 & Regime 2 \\
\hline Regime 1 & $0.8951 * * *$ & $0.2091 * * *$ \\
\hline Regime 2 & $0.1049 * * *$ & $0.7909 * * *$ \\
\hline
\end{tabular}

This table reports parameter estimates for the multivariate regimeswitching model $r_{t}=\mu_{s_{t}}+\varepsilon_{t}$, where $\mu_{s}$ is the intercept vector in state $S_{t}$ and $\varepsilon_{t} \sim N\left(0, \Sigma_{S_{t}}\right)$ is the vector of unpredictable return innovations. The unobserved state variable $S_{t}$ is governed by a first order Markov chain that can assume $k=2$ values. The two series are net returns on the DOL and $H M L_{F X}$ portfolios. The sample period is 1983:11-2021:05. Panel A $(k=1)$ represents the single-state benchmark, while Panel B refers to the two-state model. All estimates are reported monthly. Standard errors are shown in parentheses for mean coefficients.

*Significant at the $10 \%$ level, ** Significant at the $5 \%$ level, ***Significant at the $1 \%$ level.

Brumnermeier et al. (2009), who suggested that investment currencies (or high yielding currencies) may be subject to crash risk. In addition to statistical measures, several commonly used performance ones, such as the realized Sharpe ratio $(S R)$ and the realized Sortino ratio $(S O)$ are reported in Table 1 . The $S R$ is equal to the average excess return of a portfolio divided by the standard deviation of the portfolio returns, which simply measures the excess return per unit of volatility. The $S O$, unlike the $S R$, is calculated as the average excess return divided by the standard deviation of only negative returns, thereby measuring the excess return per unit of downside volatility. The $S R$ and $S O$ increase systematically when moving from portfolio 1 to portfolio 6. The annualized $S R$ ranges from -0.58 (portfolio 2) to 1.09 (portfolio 6), whereas the annualized $S O$ ranges from -0.80 (portfolio 2) to 1.57 (portfolio 6). 


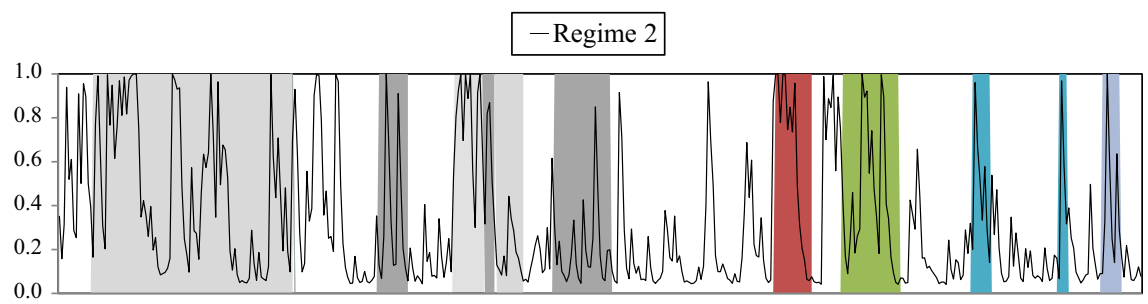

84858687888990919293949596979899000102030405060708091011121314151617181920

\begin{tabular}{|ll|}
\hline 1985-1991 Latin America dabt crisis & 1994-1995 Mexico economic crisis \\
1997-1998 Asian financial crisis & 1998 Russian financial crisis \\
1999 Brazil currency crisis & 2001-2002 Argentinian crisis \\
2008 Global financial crisis & 2010-2011 Eurozone sovereign debt crisis \\
Chinese stock market crash & 2020 COVID-19 \\
\hline Regime 2 & \\
\hline
\end{tabular}

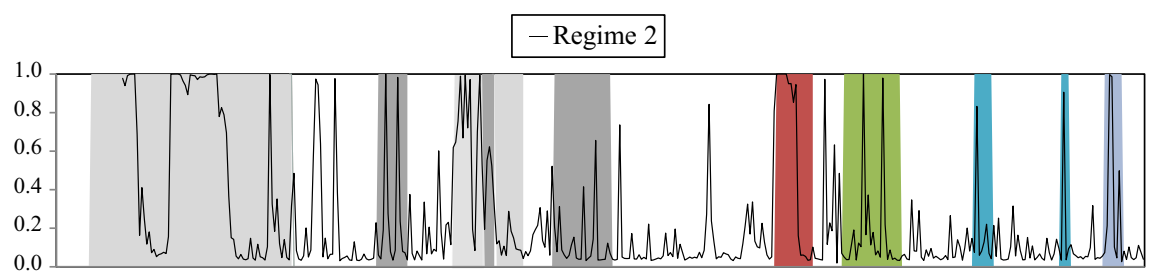

84858687888990919293949596979899000102030405060708091011121314151617181920

\begin{tabular}{|ll|}
\hline 1985-1991 Latin America dabt crisis & $1994-1995$ Mexico economic crisis \\
1997-1998 Asian financial crisis & 1998 Russian financial crisis \\
1999 Brazil currency crisis & $2001-2002$ Argentinian crisis \\
2008 Global financial crisis & $2010-2011$ Eurozone sovereign debt crisis \\
Chinese stock market crash & 2020 COVID-19 \\
\hline & Regime 2
\end{tabular}

Fig. 1 Filtered state probabilities of regime 2: two-state model for returns on $D O L$ and $H M L_{F X}$ portfolios. The top panel of graph plots the filtered state probability of regime 2 for the multivariate two-state Markov switching model, with constant transition probabilities and the bottom panel shows that with time-varying transition probabilities (TVTP). The sample period is from 1983:11 to 2021:05 and the parameter estimates underlying these plots are reported in Tables 2 and 3 , respectively

\subsection{Regimes in the joint return process}

In this section, the aim is to identify regimes in the joint process of returns on the $D O L$ and $H M L_{F X}$ portfolios $\left[r_{t}^{D O L} r_{t}^{H M L}\right]^{\prime}$. To assist in the economic interpretation of the twostate Markov regime switching model, Table 2 presents the parameter estimates, while in Fig. 1, the associated state probabilities are plotted. Regime 2 is a highly volatile bear state, the average duration of which is 4.78 months and the mean returns on both the $D O L$ and $H M L_{F X}$ portfolios are at $2.1 \%$ and $-5.51 \%$ per annum, respectively. ${ }^{4}$ During this regime, the $H M L_{F X}$ portfolio incurs a large loss, resulting in investors liquidating their carry trade positions and thus, leading to a further appreciation of low-interest rate currencies. Moreover, the traditionally regarded safe-haven currency, the U.S. dollar, also appreciates during

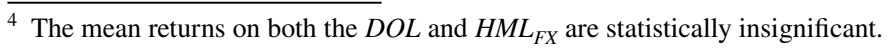


this high FX volatility state, causing a significantly positive correlation between the $D O L$ and $H M L_{F X}$. Figure 1 shows that this regime captures major currency crashes and periods with a sustained decline in currency values, such as the 1982 Latin American debt crisis, which lasted until 1991, the 1994 economic crisis in Mexico, the 1997 Asian financial crisis, the 1998 Russian financial crisis, the 1999 Brazilian currency crisis, the Argentinian crisis in 2001-2002, the 2008 global financial crisis, the 2010-2011 Eurozone sovereign debt crisis, the Chinese stock market crash in 2015-2016 and 2018 as well as the COVID19 pandemic in 2020 .

Regime 1 is a highly persistent low-volatility and high return state, with an average duration of 9.54 months, that captures the long periods with relatively stable currency values during the mid-1990s, the periods before the 2008 global financial crisis and those before the 2020 COVID-19 pandemic. Mean returns in this state are positive for the DOL and $H M L_{F X}$ portfolios (non-significantly $1.3 \%$ and significantly $8.64 \%$ per annum, respectively), thus indicating that the forward premium puzzle is strong and UIP is violated. The steady state probabilities implied by the estimates of the transition matrix $\hat{\mathrm{P}}$ are $66.6 \%$ and $33.4 \%$, respectively. Furthermore, the transition probabilities indicate that the market exits to regime 1 from regime 2 more easily (20.91\%) than vice versa (10.49\%).

\subsection{Regime predictor variables: the TED spreads}

Figure 1 seeks to interpret the economic causes behind the regimes by comparing the filtering probabilities of regime 2 with the dating of currency crises. Brunnermeier, Nagel and Pedersen (2009) elicit that liquidity is a key driver of currency crashes. Following these authors, we model the transition probabilities in the RSM as the function of the TED spreads. By implementing the RSM with time-varying transition probabilities (TVTP), we aim to ascertain whether the TED spreads can effectively predict regime change. The TED spread is defined as the interest rate difference between the 3-month Eurodollar interbank deposits (LIBOR) and 3-month Treasury bills. ${ }^{5}$ Differences between these rates reflect the willingness of banks to provide funding in the interbank market. A large spread should be related to lower liquidity and we use this measure to proxy for illiquidity in the funding market for carry trades. Table 3 presents the parameter estimates from the TVTP model. Similar to the results of constant transition probabilities, we still find two regimes. Regime 2 is a highly volatile bear state of average duration about 2 months and the mean returns on both the $D O L$ and $H M L_{F X}$ portfolios are insignificantly negative. Regime 1 is a low-volatility bull sate, with an average duration of about 9 months and the mean returns on both the $D O L$ and $H M L_{F X}$ portfolios are significantly positive at $1 \%$. The time-varying transition probabilities results show that the coefficient of the TED spreads on $P^{21}$ is -4.0604 , which is statistically significant at the $10 \%$ confidence interval. The results indicate that increases in funding liquidity risk (the wider of TED spreads) would decrease the transition probabilities of exiting from regime 2 to regime 1, thus increasing the transition probabilities of staying at the former. The evidence shows that the TED spreads can explain the regime shifts through the transition probabilities. Investors should unwind their carry trade position, if they observe an abrupt increase of TED spreads. For comparison, the filtered state probabilities of regime 2 estimated by the TVTP model are plotted in the bottom panel of Fig. 1.

5 The data availability for the TED spread is from Jan. 1986. 
Table 3 Parameter estimates of the regime-switching model for $D O L$ and $\mathrm{HML}_{\mathrm{FX}}$ returns with time-varying transition probabilities (TVTP)

DOL portfolio $H M L_{F X}$ portfolio

Sample periods: $1986 / 2-2021 / 5$

1. Mean excess return

Regime 1

$0.0024(0.0009) * * *$

$0.0066(0.0012) * * *$

Regime 2

$-0.005(0.0033)$

$-0.0075(0.0046)$

2. Correlations/Volatilities

Regime 1

$D O L$ portfolio

$H M L_{F X}$ portfolio

Regime 2

$$
D O L \text { portfolio }
$$

$H M L_{F X}$ portfolio

3. Transition matrix parameters

P11-constant

P11-TED spreads

P21-constant

P21-TED spreads

4. Mean expected durations

\section{$0.0140 * * *$}

0.1111

$0.0184 * * *$

$0.0272 * * *$

0.1413

$0.0369 * * *$

$$
\begin{aligned}
& 1.0474(0.3351)^{* * *} \\
& 0.2991(0.4546) \\
& 2.3642(1.5115) \\
& -0.4064(2.1359)^{*}
\end{aligned}
$$

\section{Regime 1}

8.76
Regime 2

1.66

This table reports parameter estimates for the multivariate regime-switching model $r_{t}=\mu_{s_{t}}+\varepsilon_{t}$, where $\mu_{s_{t}}$ is the intercept vector in state $S_{t}$ and $\varepsilon_{t} \sim N\left(0, \Sigma_{S_{t}}\right)$ is the vector of unpredictable return innovations. The unobserved state variable $S_{t}$ is governed by a first order Markov chain that can assume $k=2$ values. The two series are net returns on the DOL and $H M L_{F X}$ portfolios. The transition probabilities are $P R\left(s_{t}=i \mid s_{t-1}=j\right)=p_{t}^{j i}\left(z_{t-1}\right)$, where $P_{t}^{j i}(\cdot)$ is a function of the TED spreads and $\sum_{j} P_{t}^{j i}(\cdot)=1 \forall i, j \in\{1, \ldots, k\}$. The sample period is 1986:02-2021:05. All estimates are reported monthly. Standard errors are shown in parentheses for mean coefficients.

*Significant at the $10 \%$ level, ** Significant at the 5\% level, ***Significant at the $1 \%$ level.

\section{The asset allocation problem}

So far, we have documented the presence of regimes regarding the process underlying returns on the market and carry trade portfolios. Next, we explore the asset allocation implications of such regimes. Given that regime shifts clearly generate predictability in future investment opportunities, we expect to see interesting horizon effects and hedging demands. To investigate the optimal portfolio allocation with regime shifts, we consider the asset allocation problem of an investor with power utility over terminal wealth $W_{T}$, a coefficient of relative risk aversion $\gamma$, and time horizon $T$ :

$$
U\left(W_{T}\right)=\frac{W_{T}^{1-\gamma}}{1-\gamma}
$$

The investor is assumed to maximize expected utility by choosing at time $t$ a portfolio weight to the $D O L$ and $H M L_{F X}$ portfolios, $\omega_{t} \equiv\left[\omega_{t}^{D O L} \omega_{t}^{H M L_{F X}}\right]^{\prime}$, while any residual wealth 
is invested in riskless, 1-month T-bills. For simplicity, we assume the investor has unit initial wealth and ignores intermediate consumption, with portfolio weights being rebalanced every month.

Let $\omega_{b}$ be the weights on the currency portfolios at the rebalancing points. The investor's optimization problem is:

$$
\begin{aligned}
\max _{\left\{\omega_{j}\right\}_{j=t}^{T-1}} E_{t}\left[U\left(W_{T}\right)\right] \text { s.t. } W_{t+1}= & W_{t}\left\{\left(1-\omega_{t}^{D O L}\right) \exp \left(r^{f}\right)+\omega_{t}^{D O L} \exp \left(r_{t+1}^{D O L}+r^{f}\right)+\omega_{t}^{H M L_{F X}} r_{t+1}^{H M L_{F X}}\right\} . \\
& \left(1-\omega_{t}^{D O L}\right) \geq x \%\left|\omega_{t}^{H M L_{F X}}\right| .
\end{aligned}
$$

where $E_{t}[\cdot]$ denotes the conditional expectation given the information set at time $t, r_{t}$ is the vector of logarithmic return on assets, and $\exp \left(r^{f}\right)$ is the gross return on riskless assets. In addition, $H M L_{F X}$ is a zero-investment portfolio that requires borrowing currencies and thus, investing in another currencies. Under $\mathrm{x} \%$ margin requirements, if a proportion $\omega_{t}^{H M L_{F X}}$ is invested in $H M L_{F X}, x \% \omega_{t}^{H M L_{F X}}$ must also be invested at the riskless rate to satisfy these requirements. The total gross return after investing in $H M L_{F X}$ would be $\omega_{t}^{H M L_{F X}}\left[\exp \left(r_{t+1}^{H_{F X}}\right)-\exp \left(r_{t+1}^{L_{F X}}\right)\right]+\left|x \% \omega_{t}^{H M L_{F X}}\right| \exp \left(r^{f}\right)$, where $r_{t+1}^{H_{F X}}$ and $r_{t+1}^{L_{F X}}$ are the vectors of logarithmic return on the high and low interest rate currencies, respectively. The total gross return from investing in $H M L_{F X}$ is approximately $\omega_{t}^{H M L_{F X}}\left[r_{t+1}^{H M L}\right]+\left|x \% \omega_{t}^{H M L_{F X}}\right| \exp \left(r^{f}\right)$, being thus, as written in Eq. (6):

$$
\begin{aligned}
& W_{t+1}=W_{t}\left\{\begin{array}{l}
\left(1-\omega_{t}^{D O L}-\left|x \% \omega_{t}^{H M L_{F X}}\right|\right) \exp \left(r^{f}\right) \\
+\omega_{t}^{D O L} \exp \left(r_{t+1}^{D O L}+r^{f}\right)+\omega_{t}^{H M L_{F X}} r_{t+1}^{H M L_{F X}}+\left|x \% \omega_{t}^{H M L_{F X}}\right| \exp \left(r^{f}\right)
\end{array}\right\} \\
& =W_{t}\left\{\left(1-\omega_{t}^{D O L}\right) \exp \left(r^{f}\right)+\omega_{t}^{D O L} \exp \left(r_{t+1}^{D O L}+r^{f}\right)+\omega_{t}^{H M L_{F X}} r_{t+1}^{H M L_{F X}}\right\}
\end{aligned}
$$

We assume that the investor cannot borrow the margin requirements, or, to put it another way, no one would rationally want to lend the investor the margin at the risk-free rate and therefore, $\left(1-\omega_{t}^{D O L}-\left|x \% \omega_{t}^{H M L_{F X}}\right|\right) \geq 0 .^{6}$ In other words, we derive the constraint faced by the investor in solving the optimal asset allocation problem: $\left(1-\omega_{t}^{D O L}\right) \geq x \%\left|\omega_{t}^{H M L_{F X}}\right|$. In the paper, we assume $\mathrm{x}=5$.

Up to this point, no specific DGP has been assumed for the asset returns and hence, the setup of the problem is general. In the special case of $r_{t+1}$ i.i.d. across time, Samuelson (1969) shows that for the CRRA utility the portfolio weights are constant, and the $T$ horizon problem becomes equivalent to solving the myopic $T=1$ one-period problem. When returns are not i.i.d., then the portfolio weights can be broken down into a myopic and a hedging component (Merton, 1971), with the former being the solution from solving the one-period problem, whereas the latter results from the investor's desire to hedge against unfavorable changes in the investment opportunity set.

Suppose we introduce an RSM into the DGP, then the derived utility of wealth is:

\footnotetext{
${ }^{6}$ For example, under $5 \%$ margin requirements, a position of $467 \%$ in $H M L_{F X}$ requires an investor to hold $23.35 \%(5 \% * 467 \%)$ in T-bills. Since the investor cannot borrow the margin requirements, after putting (say) $80 \%$ in the DOL portfolio, only $20 \%$ of the initial wealth is available. Therefore, the investor will have to adjust (lower) their holdings in $D O L$ or $H M L_{F X}$ to fulfill the margin requirement, i.e., $\left(1-\omega_{t}^{D O L}-\left|x \% \omega_{t}^{H M L_{F X}}\right|\right) \geq 0$ must be held.
} 


$$
J\left(W_{t}, r_{t}, \theta, \pi_{t}\right) \equiv \max _{\left\{\omega_{j}\right\}_{j=t}^{T-1}} E_{t}\left[U\left(W_{T}\right]\right.
$$

where $\theta=\left(\left\{\mu_{i}, \sum_{i}\right\}_{i=1}^{k}, P\right)$ collects the parameters of the RSM, and $\pi_{t}$ is the state probabilities at point $t$. Treating states as unobserved is consistent with the estimation problem solved by the investors, where the regime can only be inferred from the available data. From the derivation of Hamilton (1994, p.692-693), investors' learning process is incorporated by letting them update their beliefs about the underlying state at each point in time using Bayes' rule:

$$
\pi_{t+1}(\theta)=\frac{\pi_{t}(\theta) P \odot \eta\left(r_{r+1} ; \theta\right)}{\left(\pi_{t}(\theta) P \odot \eta\left(r_{r+1} ; \theta\right)\right) l_{k}}
$$

where $\odot$ denotes the element-by-element product and $\eta\left(r_{t+1}\right)$ is a $k \times 1$ vector that gives the density of observation $r_{t+1}$ in the $k$ states at time ${ }_{t+1}$ conditional on $\theta$ :

$$
\begin{aligned}
\eta\left(r_{t+1} ; \theta\right) \equiv\left[\begin{array}{c}
f\left(r_{t+1} \mid s_{t+1}=1, \theta\right. \\
f\left(r_{t+1} \mid s_{t+1}=2, \theta\right. \\
\vdots \\
f\left(r_{t+1} \mid s_{t+1}=k, \theta\right.
\end{array}\right] \\
=\left[\begin{array}{c}
(2 \pi)^{-1}\left|\Sigma_{1}^{-1}\right|^{\frac{1}{2}} \exp \left[-\frac{1}{2}\left(r_{t}-\mu_{1}\right)^{\prime} \Sigma_{1}^{-1}\left(r_{t}-\mu_{1}\right)\right] \\
(2 \pi)^{-1}\left|\Sigma_{2}^{-1}\right|^{\frac{1}{2}} \exp \left[-\frac{1}{2}\left(r_{t}-\mu_{1}\right)^{\prime} \Sigma_{2}^{-1}\left(r_{t}-\mu_{2}\right)\right] \\
\vdots \\
(2 \pi)^{-1}\left|\Sigma_{k}^{-1}\right|^{\frac{1}{2}} \exp \left[-\frac{1}{2}\left(r_{t}-\mu_{k}\right)^{\prime} \Sigma_{1}^{-1}\left(r_{t}-\mu_{k}\right)\right]
\end{array}\right]
\end{aligned}
$$

Learning effects are important since portfolio choices depend not only on future values of asset returns, but also, future perceptions of the probability of being in each of the regimes. Given that $W t$ is known at time $t$, the scaled value function $Q(\cdot)$ simplifies to:

$$
Q\left(r_{t}, \pi_{t}\right)=\max _{\omega_{t}} E_{t}\left[\left(\frac{W_{t+1}}{W_{t}}\right)^{1-\gamma} Q\left(r_{t+1}, \pi_{t+1}\right)\right] .
$$

Conditional on the current parameter estimates $\hat{\theta}$, the optimal portfolio weights reflect not only hedging demands due to stochastic shifts in investment opportunities, but also, changes in investors' beliefs concerning future state probabilities $\pi_{t+1}$.

\subsection{Numerical solution}

Past literature has applied different solution methods on portfolio allocation under timevarying investment opportunities. For example, Campbell and Viceira (1999) derive approximate analytical solutions for an infinitely lived investor with continuous rebalancing, whereas Barberis (2000) applies simulation methods to study an optimal allocation problem. Ang and Bekaert (2002) solve the dynamic portfolio choice problem of a U.S. investor faced with a time-varying investment opportunity set modeled using a regimeswitching process, by considering asset allocation when the regimes are observable to investors. Guidolin and Timmermann (2008) calculate asset allocations under optimal 
filtering, thus allowing for unobservable states and in this paper we follow the methodology proposed by them. Accordingly, investors have to account for revisions in future beliefs $\pi_{t+1}$ when determining optimal asset allocations. Under this setting, we use Monte Carlo methods for expected utility approximation to solve for the portfolio weights. For a buy-and-hold investor the expected utility function can be written as follows:

$$
\max _{\omega_{t}(T)} N^{-1} \sum_{n=1}^{N}\left\{\frac{1}{1-\gamma}\left[\left(1-\omega_{t}^{D O L}\right) \exp \left(T r^{f}\right)+\omega_{t}^{D O L} \exp \left(r_{T, n}^{D O L}+T r^{f}\right)+\omega_{t}^{H M L_{F X}} r_{T, n}^{H M L_{F X}}\right]^{1-\gamma}\right\}
$$

where $r_{T, n}^{j}\left(j=D O L, H M L_{F X}\right)$ are the cumulative returns in the nth Monte Carlo simulation. Each simulated path of portfolio returns is generated by the estimated RSM, which allows regimes to shift randomly, as governed by the transition matrix $\widehat{P}$. We use $N=30,000$ simulations and vary the investment horizon $\mathrm{T}$ between 1 and 120 months. The optimal weights $\widehat{\omega}_{t}(T)$ are determined over a two-dimensional grid, $\omega_{t}^{i}(T)=-5,-4.99,-4.98, \ldots, 4.99,5.00$ for $1=D O L$ and $H M L_{F X}$. As our solution does not rule out short sales, it is possible that wealth can become negative and to account for such cases, we assume that the investor goes bankrupt and his wealth continues at zero forever, if it becomes so.

\section{Empirical results of asset allocation}

\subsection{Buy-and-hold investor}

First, we investigate the asset allocation strategy for a buy-and-hold investor. In accordance with the past literature, we report the general results for the risk aversion levels of $\gamma=5$. We provide implications of asset allocation results from the following perspective: first, as the filtered state probabilities contain information about the joint distribution of future asset returns, the optimal portfolio weights should exhibit short-term market timing effects, depending on the characteristics of the underlying regimes, such as their means, variances and covariances as well as higher order moments of asset returns within and across them. However, as the holding horizon grows, optimal portfolio weights increasingly reflect the properties of the unconditional distribution of returns and decreasingly depend on the initial state probabilities.

Figure 2 shows the plotted optimal portfolio weights varying with the investment horizon, assuming that the investor knows the initial state, but cannot identify future ones, under the risk aversion levels of $\gamma=5$. The figure shows that optimal weights vary significantly across regimes, especially at short investment horizons, where market timing effects are strong. Regime 2 is dominated by the negative mean return on the $H M L_{F X}$ portfolio. Starting from this state, the short-run allocation to the $H M L_{F X}$ portfolio is, therefore, negative (short position), though it rises in $T$. Hence, an investor should hold a long position on the $D O L$ portfolio, because of its positive mean returns. In addition, the weights on the $D O L$ portfolio decrease as a function of the horizon, $T$. Regime1 is akin to a strong forward premium puzzle. Due to its high mean return, the $H M L_{F X}$ portfolio features prominently in the optimal asset allocation, with a weight of over $400 \%$ at short horizons, which declines with the investment horizon, $T$. The positive mean return on the $D O L$ portfolio also attributes a weight to the $D O L$ of over $70 \%$ at short horizons, which falls gradually with the horizon $T$. At the 10-year horizon, about $64 \%$ is held in the DOL portfolio, $126 \%$ in the $H M L_{F X}$ portfolio, and $36 \%$ in T-bills. In addition, our long-run allocations indicate that the 

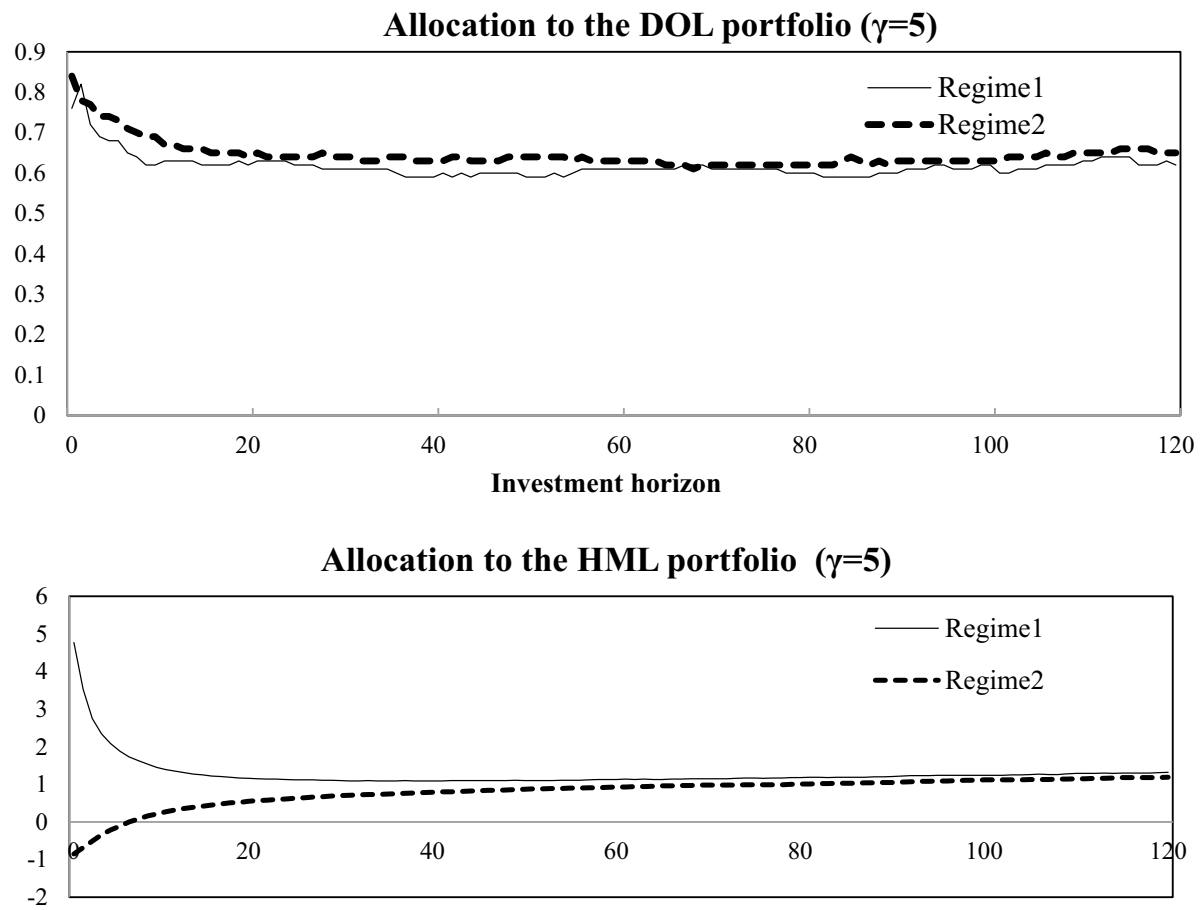

Investment horizon

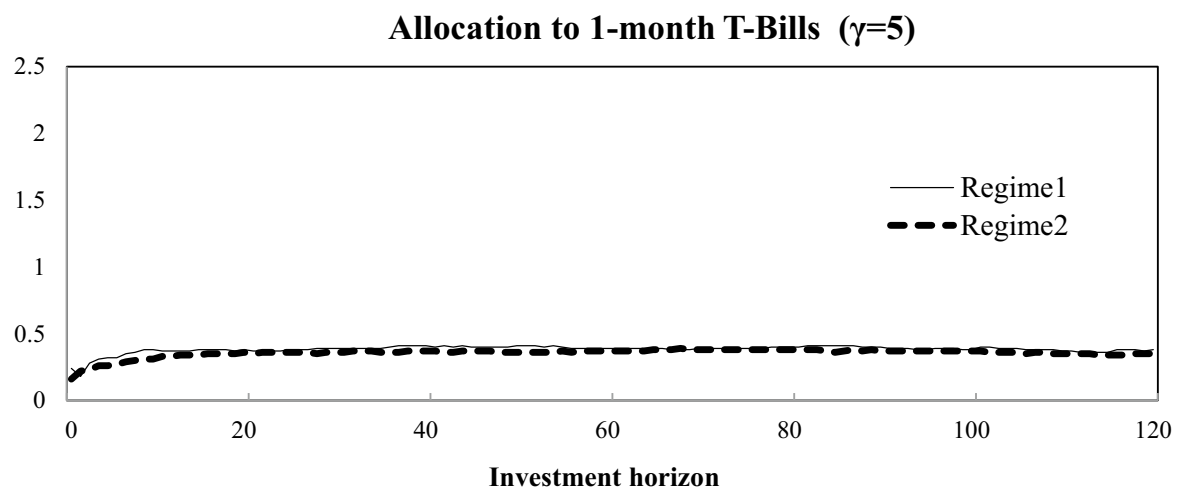

Fig. 2 Optimal asset allocation as a function of the investment horizon $(\gamma=5)$. The graphs show the optimal allocation to currency portfolios $\left(D O L\right.$ and $\left.H M L_{F X}\right)$ and risk-free T-bills under a two-state regime switching model as a function of the investment horizon for an investor with a constant coefficient of relative risk aversion $\gamma=5$. Each schedule corresponds to a different value of the initial state probabilities, while future states remain unknown and unobservable to investors

$H M L_{F X}$ portfolio is positive, which is consistent with the argument of past literature that the carry trade is profitable, on average, in the long-run. 
Allocation to the DOL portfolio $(\gamma=5)$

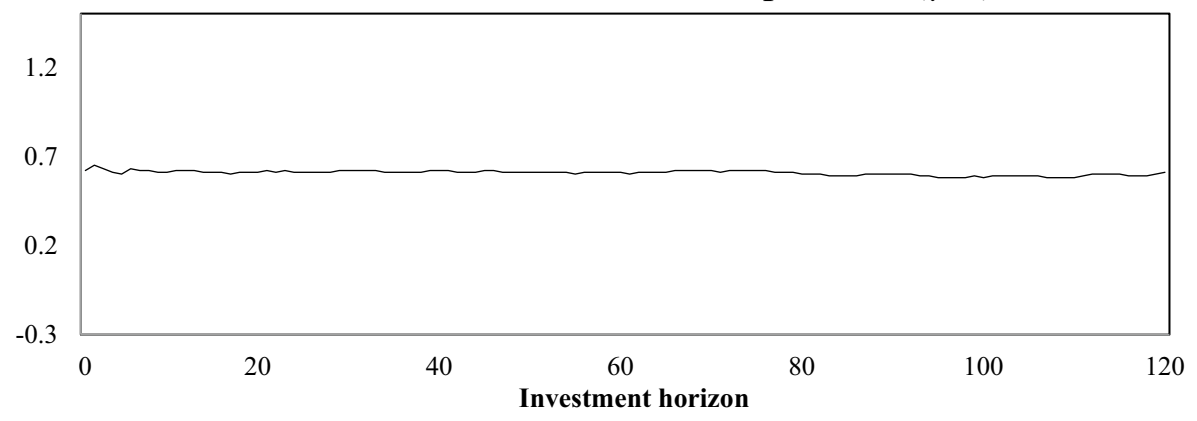

Allocation to the HML portfolio $(\gamma=5)$

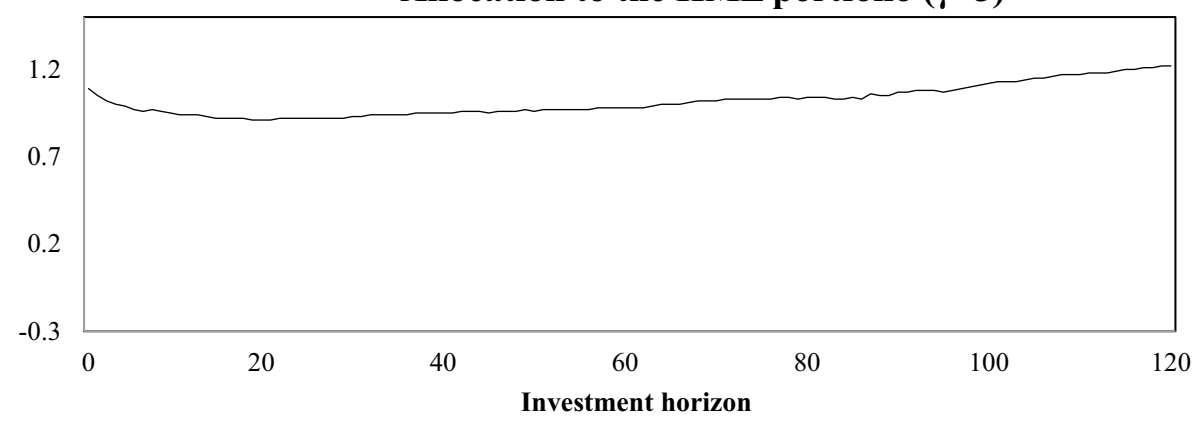

Allocation to the 1-month T-Bill $(\gamma=5)$

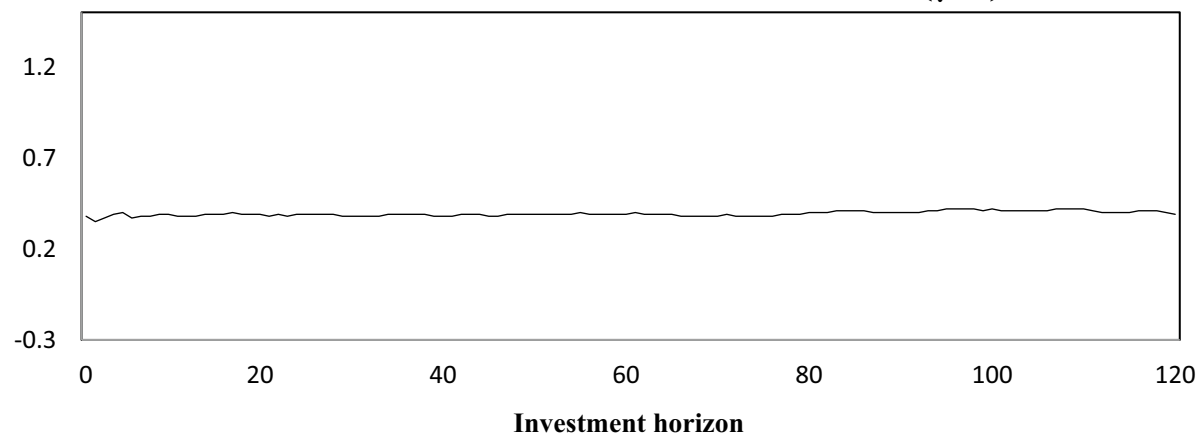

Fig. 3 Optimal asset allocation under uncertainty about the initial state $(\gamma=5)$. The graphs show the optimal allocation to currency portfolios (DOL and $H M L_{F X}$ ) and T-bills under a two-state regime switching model in which the initial state probabilities are set at their steady-state values of $\pi_{t}=[0.6660 .334]^{\prime}$. The graphs plot optimal portfolio shares as a function of the investment horizon for an investor with a constant coefficient of relative risk aversion $\gamma=5$

\subsection{Uncertainty about the states}

Figure 3 shows the results for the case where the investor is uncertain about the identity of both the initial and future states under risk aversion levels of $\gamma=5$. Accounting for this uncertainty, we assume the initial state probabilities are equal to the steady state values, $\pi_{t}=[0.6660 .334]^{\prime}$. The figure shows that the shape for the allocation that maps the optimal 
Table 4 Optimal portfolio weights under rebalancing $(\gamma=5)$
Rebalancing frequency $\varphi$ Investment horizon T (months)

$$
\begin{array}{lllll}
\mathrm{T}=1 & \mathrm{~T}=6 & \mathrm{~T}=12 & \mathrm{~T}=24 & \mathrm{~T}=120
\end{array}
$$

Panel A: DOL portfolio

Regime 1

$\begin{array}{llllll}\varphi=\mathrm{T} \text { (buy-and-hold) } & 0.76 & 0.68 & 0.63 & 0.63 & 0.62 \\ \varphi=12 \text { months } & \text { NA } & \text { NA } & \text { NA } & 0.58 & 0.60 \\ \varphi=6 \text { months } & \text { NA } & \text { NA } & 0.65 & 0.56 & 0.63 \\ \varphi=1 \text { months } & \text { NA } & 0.77 & 0.77 & 0.76 & 0.77\end{array}$

Regime 2

\begin{tabular}{|c|c|c|c|c|}
\hline$\varphi=\mathrm{T}$ (buy-and-hold) & 0.84 & 0.73 & 0.67 & 0.64 \\
\hline$\varphi=12$ months & NA & NA & NA & 0.65 \\
\hline$\varphi=6$ months & NA & NA & 0.67 & 0.70 \\
\hline$\varphi=1$ months & NA & 0.74 & 0.79 & 0.83 \\
\hline teady-state probabilitie & & & & \\
\hline$\varphi=\mathrm{T}$ (buy-and-hold) & 0.62 & 0.63 & 0.62 & 0.61 \\
\hline$\varphi=12$ months & NA & NA & NA & 0.62 \\
\hline$\varphi=6$ months & NA & NA & 0.68 & 0.66 \\
\hline$\varphi=1$ months & NA & 0.68 & 0.71 & 0.66 \\
\hline
\end{tabular}

Panel B: $H M L_{F X}$ portfolio

Regime 1

$\begin{array}{llllll}\varphi=\mathrm{T} \text { (buy-and-hold) } & 4.77 & 1.88 & 1.35 & 1.13 & 1.32 \\ \varphi=12 \text { months } & \text { NA } & \text { NA } & \text { NA } & 1.33 & 1.34 \\ \varphi=6 \text { months } & \text { NA } & \text { NA } & 1.81 & 1.81 & 1.79 \\ \varphi=1 \text { months } & \text { NA } & 4.56 & 4.60 & 4.72 & 4.52\end{array}$

Regime 2

$\begin{array}{llllll}\varphi=\mathrm{T} \text { (buy-and-hold) } & -0.85 & -0.11 & 0.32 & 0.61 & 1.19 \\ \varphi=12 \text { months } & \text { NA } & \text { NA } & \text { NA } & 0.32 & 0.30 \\ \varphi=6 \text { months } & \text { NA } & \text { NA } & -0.12 & -0.13 & -0.14 \\ \varphi=1 \text { months } & \text { NA } & -0.82 & -0.88 & -0.95 & -0.88 \\ \begin{array}{lllll}\text { Steady-state probabilities } \\ \varphi=\mathrm{T} \text { (buy-and-hold) }\end{array} & 1.09 & 0.97 & 0.94 & 0.92 & 1.22 \\ \varphi=12 \text { months } & \text { NA } & \text { NA } & \text { NA } & 0.92 & 0.91 \\ \varphi=6 \text { months } & \text { NA } & \text { NA } & 0.98 & 0.93 & 1.02 \\ \varphi=1 \text { months } & \text { NA } & 1.16 & 1.03 & 0.99 & 1.14\end{array}$

This table reports optimal weights on the $D O L$ (Panel A) and $H M L_{F X}$ (Panel B) portfolios as a function of the rebalancing frequency $\varphi$ for an investor, with a coefficient of relative risk aversion of 5. Returns are assumed to be generated by a two-state regime-switching model. Allocations marked as "NA" have $\varphi \geq \mathrm{T}$ and imply portfolio weights identical to the buy-and-hold case

weights against the investment horizon is not as steep as that in Fig. 2, where the initial state was known by the investor. The shape appears to be dominated by the optimal weights when starting from state 1 , which is a reflection of the high steady state probability in the latter state. Moreover, the 10-year horizon weights are close to those reported before in Fig. 2, being $61 \%$ in the $D O L$ portfolio, $122 \%$ in the $H M L_{F X}$ one, and $39 \%$ in T-bills. 


\subsection{Rebalancing and optimal portfolio allocation}

In the previous section, we have studied the optimal portfolio allocation for a buy-andhold investor. However, investors may want to rebalance their portfolios, rather than buyand-hold for whole periods. Table 4 presents the results for optimal weights rebalancing every 1,6 or 12 months under risk aversion levels of $\gamma=5$. It can be seen that the horizon effect on these weights is not as strong for the frequent rebalancing investor as for the buyand-hold one. Furthermore, an investor who can rebalance portfolios more frequently will respond more aggressively to the current state, because they can simply adjust the portfolio weight, if the perceived state probabilities change in the next period.

From Table 4, it can be observed that the rebalancing frequency can have a large effect on asset holdings, particularly when the rebalancing frequency is varied from $\varphi=12$ to $\varphi=1$ at a 10 -year horizon in state 1 . That is, the weight on the $D O L$ portfolio increases from 60 to $77 \%$, and that on the $H M L_{F X}$ portfolio increases from 134 to $452 \%$. In addition, under monthly rebalancing, an investor will increase holdings in both the $D O L$ and $H M L_{F X}$ portfolios largely due to the high mean returns for both portfolios in state 1 . In contrast, moving to $\varphi=1$ and starting from regime 1 , a switch to state 2 may occur prior to the next rebalancing point and since $H M L_{F X}$ has negative mean returns in this state, the weights on it are reduced substantially when compared to the case with $\varphi=12$.

Furthermore, a large variation can be seen across states in the portfolio weights under rebalancing. For example, the long-run allocation to $H M L_{F X}$ goes from a negative value in state 2 (about $-88 \%$ ) to values greater than four in state 1 (about $452 \%$ ) when $\varphi=1$. Conversely, as rebalancing happens less frequently, the variations across states in the portfolio weights become less. For instance, the long-run allocation to $H M L_{F X}$ goes from a small positive value in state 2 (about 30\%) to values greater than one in state 1 (about 134\%) when $\varphi=12$.

For comparison, we also report the results for optimal weights rebalancing under risk aversion levels of $\gamma=10$ in Table 5. Generally, the pattern under this aversion level is similar to that under $\gamma=5$, as was discussed above. But the risk-averse investors $(\gamma=10)$ intend to hold (or short) less risky assets $\left(D O L, H M L_{F X}\right)$ during both regimes, with even fewer such assets under a bear regime (regime 2).

\section{Economic importance of regimes}

So far, we have shown that regime shifts can have a large effect on the optimal asset allocation. However, whether ignoring regimes will lead to a significant loss in portfolio returns still needs to be examined. To assess the economic importance of regimes, we consider an out of sample performance of pairs of model specifications: the single-state Gaussian IID model, and the regime-switching model, with constant and time-varying transition probabilities, respectively.

\subsection{Out of sample performance}

To quantify the portfolio performance improvement by using RSMs, we employ an out of sample asset allocation experiment for the period 2000:01-2021:05. In the experiment, we focus on the buy-and-hold portfolio problem at investment horizon 
Table 5 Optimal portfolio weights under rebalancing $(\gamma=10)$
Rebalancing frequency $\varphi$ Investment horizon $\mathrm{T}$ (months)

$\begin{array}{lllll}\mathrm{T}=1 & \mathrm{~T}=6 & \mathrm{~T}=12 & \mathrm{~T}=24 & \mathrm{~T}=120\end{array}$

Panel A: DOL portfolio

Regime 1

$\begin{array}{llllll}\varphi=\mathrm{T} \text { (buy-and-hold) } & 0.56 & 0.35 & 0.32 & 0.32 & 0.32 \\ \varphi=12 \text { months } & \text { NA } & \text { NA } & \text { NA } & 0.30 & 0.31 \\ \varphi=6 \text { months } & \text { NA } & \text { NA } & 0.34 & 0.29 & 0.33 \\ \varphi=1 \text { months } & \text { NA } & 0.68 & 0.72 & 0.69 & 0.63\end{array}$

Regime 2

$\begin{array}{llllll}\varphi=\mathrm{T} \text { (buy-and-hold) } & 0.42 & 0.36 & 0.33 & 0.32 & 0.33 \\ \varphi=12 \text { months } & \text { NA } & \text { NA } & \text { NA } & 0.33 & 0.32 \\ \varphi=6 \text { months } & \text { NA } & \text { NA } & 0.33 & 0.35 & 0.35 \\ \varphi=1 \text { months } & \text { NA } & 0.37 & 0.40 & 0.41 & 0.37 \\ \text { Steady-state probabilities } & & & & & \\ \varphi=\mathrm{T} \text { (buy-and-hold) } & 0.31 & 0.32 & 0.32 & 0.31 & 0.32 \\ \varphi=12 \text { months } & \text { NA } & \text { NA } & \text { NA } & 0.32 & 0.31 \\ \varphi=6 \text { months } & \text { NA } & \text { NA } & 0.34 & 0.33 & 0.32 \\ \varphi=1 \text { months } & \text { NA } & 0.34 & 0.36 & 0.33 & 0.37\end{array}$

Panel B: $H M L_{F X}$ portfolio

Regime 1

$\begin{array}{llllll}\varphi=\mathrm{T} \text { (buy-and-hold) } & 2.40 & 0.97 & 0.69 & 0.58 & 0.68 \\ \varphi=12 \text { months } & \text { NA } & \text { NA } & \text { NA } & 0.68 & 0.68 \\ \varphi=6 \text { months } & \text { NA } & \text { NA } & 0.92 & 0.91 & 0.91 \\ \varphi=1 \text { months } & \text { NA } & 2.28 & 2.30 & 2.36 & 2.26\end{array}$

Regime 2

\begin{tabular}{llllrc}
$\varphi=\mathrm{T}$ (buy-and-hold) & -0.43 & -0.05 & 0.16 & 0.31 & 0.60 \\
$\varphi=12$ months & NA & NA & NA & 0.16 & 0.15 \\
$\varphi=6$ months & NA & NA & -0.06 & -0.07 & -0.07 \\
$\varphi=1$ months & NA & -0.41 & -0.44 & -0.48 & -0.44 \\
Steady-state probabilities & & & & & \\
$\varphi=\mathrm{T}$ (buy-and-hold) & 0.55 & 0.49 & 0.48 & 0.47 & 0.62 \\
$\varphi=12$ months & NA & NA & NA & 0.47 & 0.46 \\
$\varphi=6$ months & NA & NA & 0.49 & 0.47 & 0.51 \\
$\varphi=1$ months & NA & 0.58 & 0.51 & 0.49 & 0.56 \\
\hline
\end{tabular}

This table reports optimal weights on the DOL (Panel A) and $H M L_{F X}$ (Panel B) portfolios as a function of the rebalancing frequency $\varphi$ for an investor, with a coefficient of relative risk aversion of 10. Returns are assumed to be generated by a two-state regime-switching model. Allocations marked as "NA" have $\varphi \geq \mathrm{T}$ and imply portfolio weights identical to the buy-and-hold case.

$T=1$ month. We compare the performance of a single state Gaussian IID model, and the two-state RSM with constant and time-varying transition probabilities, respectively. We use the realized portfolio returns to assess investment performance and given a particular portfolio weight $\widehat{\omega_{t}^{T}}$, realized portfolio returns $R_{T}\left(\widehat{\omega}_{t}^{T}\right)$ can be written as follows: 
Table 6 Real-time out of sample performance of predictability models

\begin{tabular}{|c|c|c|c|c|c|}
\hline & Gaussian I.I.D & $\begin{array}{l}\text { Two-State (con- } \\
\text { stant transition } \\
\text { probabilities) }\end{array}$ & Two-State (TVTP) & Carry trade & Buy-and-hold \\
\hline \multicolumn{6}{|l|}{ Panel A: $\gamma=5$} \\
\hline $\begin{array}{l}\text { Mean returns } \\
\text { (annualized) }\end{array}$ & 0.053 & 0.084 & 0.132 & 0.046 & 0.047 \\
\hline SD (annualized) & 0.384 & 0.633 & 0.757 & 0.265 & 0.290 \\
\hline Sharpe ratio & 0.098 & 0.108 & 0.153 & 0.114 & 0.110 \\
\hline Cumulative returns & 1.131 & 1.796 & 2.819 & 0.975 & 1.012 \\
\hline Max 1-month loss & -0.150 & -0.167 & -0.189 & -0.078 & -0.101 \\
\hline $\begin{array}{l}\text { Maximum draw- } \\
\text { down }\end{array}$ & 0.434 & 0.988 & 0.714 & 0.113 & 0.112 \\
\hline Sortino ratio & 0.136 & 0.175 & 0.261 & 0.167 & 0.157 \\
\hline \multicolumn{6}{|l|}{ Panel B: $\gamma=10$} \\
\hline $\begin{array}{l}\text { Mean returns } \\
\text { (annualized) }\end{array}$ & 0.034 & 0.052 & 0.079 & 0.046 & 0.031 \\
\hline SD (annualized) & 0.193 & 0.340 & 0.415 & 0.265 & 0.147 \\
\hline $\begin{array}{l}\text { Sharpe ratio (per } \\
\text { month) }\end{array}$ & 0.097 & 0.109 & 0.192 & 0.114 & 0.108 \\
\hline Cumulative returns & 0.731 & 1.122 & 1.700 & 0.975 & 0.671 \\
\hline Max 1-month loss & -0.074 & -0.105 & -0.103 & -0.078 & -0.050 \\
\hline $\begin{array}{l}\text { Maximum draw- } \\
\text { down }\end{array}$ & 0.216 & 0.496 & 0.414 & 0.113 & 0.055 \\
\hline Sortino ratio & 0.136 & 0.175 & 0.262 & 0.167 & 0.157 \\
\hline
\end{tabular}

This table reports out of sample performance measures for the investment horizons: $T=1$ month. The performance measures are computed under an alternative model for the joint process of portfolio returns

$$
R_{T}\left(\widehat{\omega}_{t}^{T}\right) \equiv\left(1-\widehat{\omega}_{t}^{D O L}\right) \operatorname{Tr}^{f}+\widehat{\omega}_{t}^{D O L}\left(r_{t}^{D O L}+T^{f}\right)+\widehat{\omega}_{t}^{H M L_{F X}} r_{T}^{H M L_{F X}}
$$

where $r_{T}^{D O L}$ and $r_{T}^{H M L_{F X}}$ are realized cumulated returns between $t+1$ and $t+1$. The period- $t$ weights $\hat{\omega}_{t}$ are solved by maximizing the objective expected utility at time $t$. Hence, for each investment horizon $\mathrm{T}$, we obtain the time series $\left\{R_{T}\left(\widehat{\omega}_{\tau}^{T}\right)\right\}, \tau=2000: 01, \ldots, 2021: 05-\mathrm{T}$ of realized portfolio returns. We use a "recursive" scheme, gradually including more recent observations in the parameter estimation windows. This scheme retains the entire history in the training sample, causing its window size gradually to increase. For instance, to predict the return distribution for 2002:01, the parameter estimates are based on the information from 1983:11 to 2001:12 and the estimates are updated recursively through time.

Table 6 reports summary statistics for the out of sample portfolio returns $\left\{R_{T}\left(\widehat{\omega}_{\tau}^{T}\right)\right\}$ from the single-state Gaussian IID model, and the two-state RSM, with both constant and time-varying transition probabilities (TVTP), respectively. For comparison, we also include a buy-and-hold and carry trade strategy in the table. ${ }^{7}$ We define the maximum drawdown of a strategy as:

\footnotetext{
${ }^{7}$ Our buy-and-hold strategy is defined as buying constant weights in DOL, $H M L_{F X}$ and T-bills and hold for the whole out of sample periods. The constant initial weight is determined by the singlestate Gaussian IID model. For $\gamma=5, \omega^{\mathrm{DOL}}=0.37, \omega^{\mathrm{HML}_{\mathrm{Fx}}}=0.97, \omega^{r f}=0.63$. In addition, for $\gamma=10$, $\omega^{\mathrm{DOL}}=0.18, \omega^{\mathrm{HML}}{ }_{\mathrm{Fx}}=0.49, \omega^{r f}=0.82$.
} 


$$
\operatorname{MaxDD}=\max _{0 \leq t_{1} \leq t_{2} \leq T}\left(Y_{t_{1}}-Y_{t_{2}}\right)
$$

where $Y_{t}$ is the cumulative log return from date 0 through $t$.

From Table 6, we observe that the two-state models both with constant and time-varying transition probabilities generate higher mean returns, cumulative returns and Sortino ratio than the single-state Gaussian IID model, carry trade and buy-and-hold strategy for both $\gamma=5$ and 10. For instance, for $\gamma=5$, the two-state models with constant and time-varying transition probabilities generate annualized mean returns of $8.4 \%$ and $13.2 \%$, respectively, as opposed to $5.3 \%, 4.6 \%$ and $4.7 \%$ for the single-state Gaussian IID model, carry trade and buy-and-hold strategies. However, the returns produced by the RSM tend to be more volatile than those produced by the latter model, thus causing large standard deviations, maximum 1-month losses and maximum drawdown. Overall, the RSM with time-varying transition probabilities (TVTP) can generate the highest Sharpe ratio, that is, 0.153 for $\gamma=5$ and 0.192 for $\gamma=10$, among the five different strategies.

Figure 4 exhibits the out of sample portfolio weights for the two-state model, with time-varying transition probabilities (TVTP) under $\gamma=5$. The weights reflect regime shifts, suggesting that during the periods where the probability of state 1 is high, investors tend to allocate more in both the $H M L_{F X}$ and DOL portfolios than the weights indicated by a single state Gaussian IID model. While during the periods where the probability of state 2 is high, investors would allocate their wealth more to 1-month T-bills (the U.S. dollar). Particularly during the 2008 global financial crisis periods, the weights in T-bills reached as high as $281 \%$. The investors' behavior demonstrates that the U.S. dollar served as the safe haven currency during the crisis periods. However, during the COVID-19 pandemic, the weights in T-bills were not as high as those indicated in the 2008 global financial crisis periods. As Fig. 5 shows, during the pandemic, the deterioration of the returns of $D O L$ accelerated between mid-February and late March 2020. Since the beginning of April 2020, the returns of DOL have started to slowly recover, a rebound that may be due to the fact that the Federal Reserve System was creating massive amounts of dollars at an unprecedented rate during the COVID-19 pandemic, thus weakening the value of the U.S. dollar (USD). In the COVID-19 pandemic, the low return pattern in the $D O L$ did not persist as much as during the 2008 global financial crisis. Hence, as can be seen, the weights in T-bills were not as high in the former as during the latter.

Figure 6 exhibits the out of sample month-to-month cumulative returns for the twostate RSM, with constant and time-varying transition probabilities, respectively, the single-state Gaussian IID model, carry trade as well as a buy-and-hold strategy under the setting $\gamma=5$. It clearly confirms that the two-state model with time-varying transition probabilities (TVTP) earned its return in quite a stable fashion, with more upswings than downswings. In contrast, the carry trade and buy-and-hold strategy as well as the single-state Gaussian IID model suffered some major declines from weak performances of the $H M L_{F X}$ portfolio due to the occurrence of major currency crisis events, particularly during the 2008 global financial crisis. The two-state RSM partially anticipated these peso events as well as the changes of the related economic fundamentals, which strongly served the overall performance of the portfolio. 

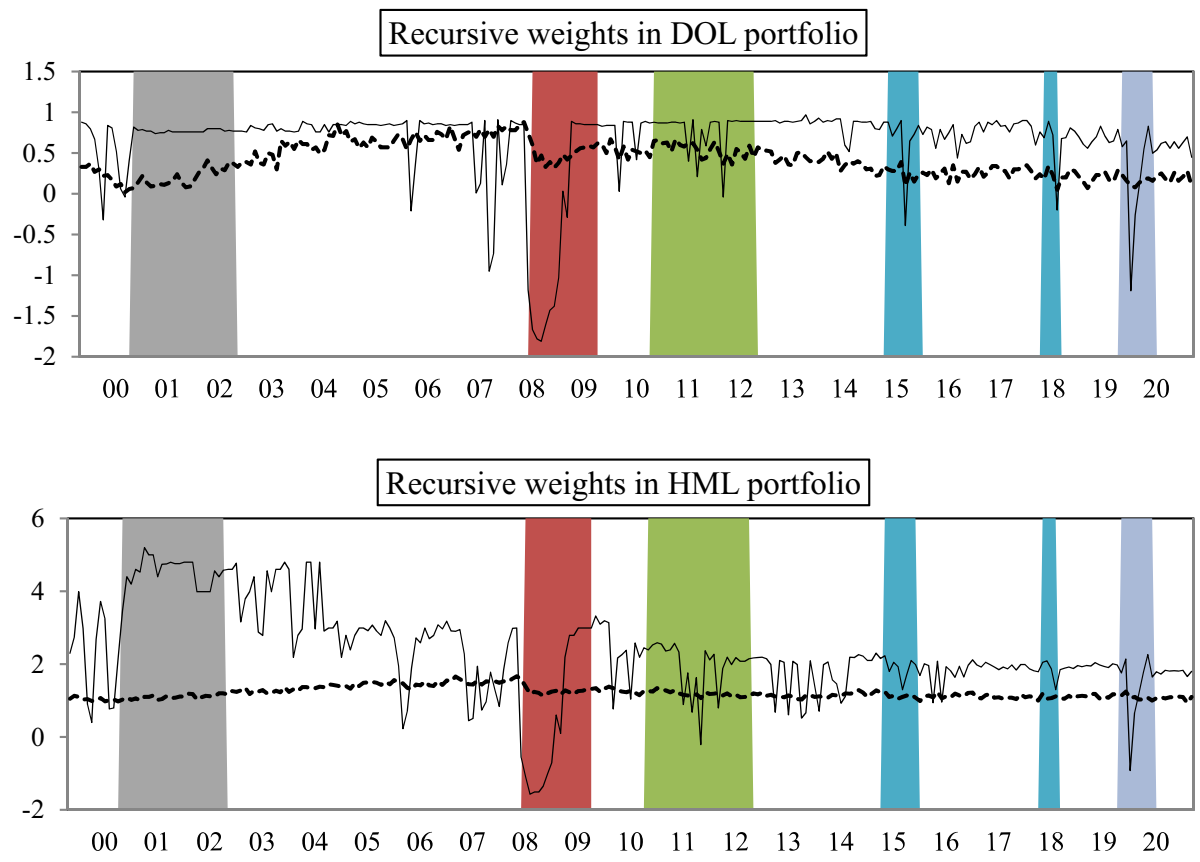

\section{Recursive weights in T-Bill}

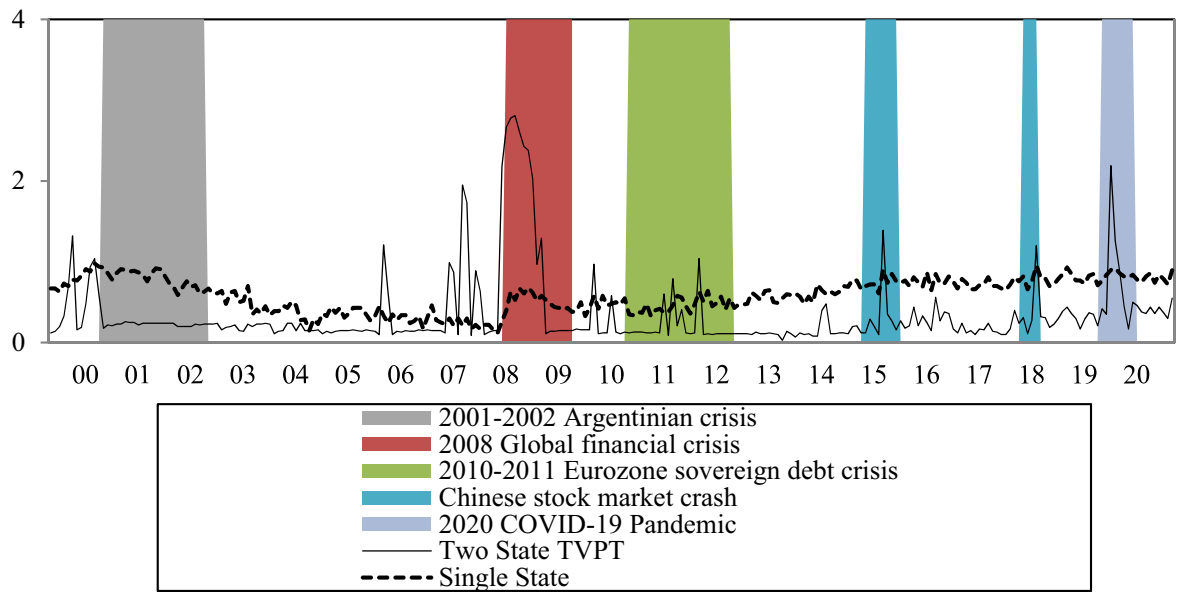

Fig. 4 Out of sample recursive weights under alternative models $(\gamma=5)$. The graphs show the evolution in the allocation to currency portfolios (DOL and $H M L_{F X}$ ) and T-bills for an investor with a constant coefficient of relative risk aversion $\gamma=5$ and a 1-month horizon. Models and weights are updated recursively over the period 2000:01-2021:05. The two models are a single-state Gaussian IID and a two-state regime switching one, with time-varying transition probabilities (TVTP) 


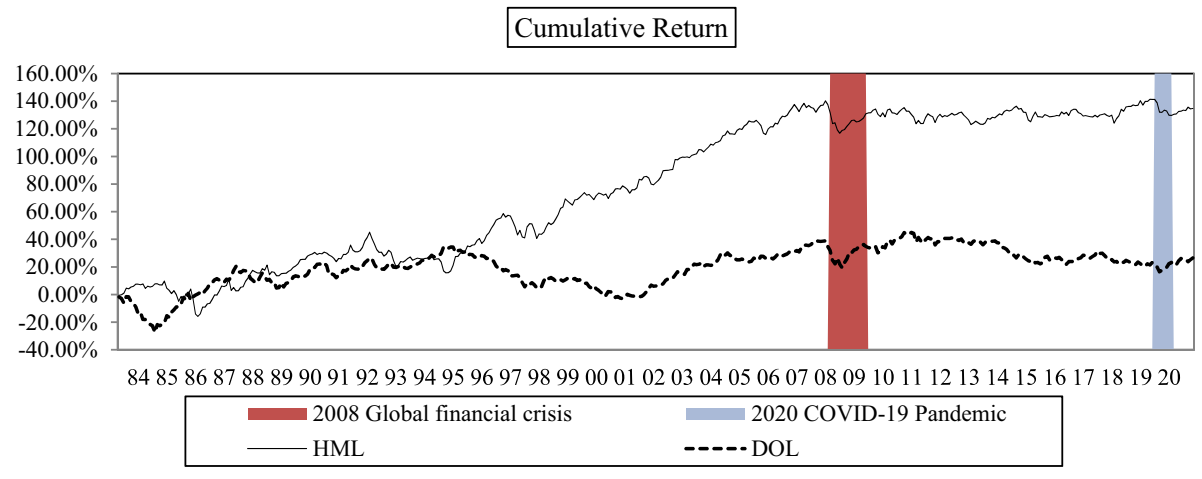

Fig. 5 Cumulative month-to-month returns for the $D O L$ and $H M L_{F X}$

\section{Cumulative Return}

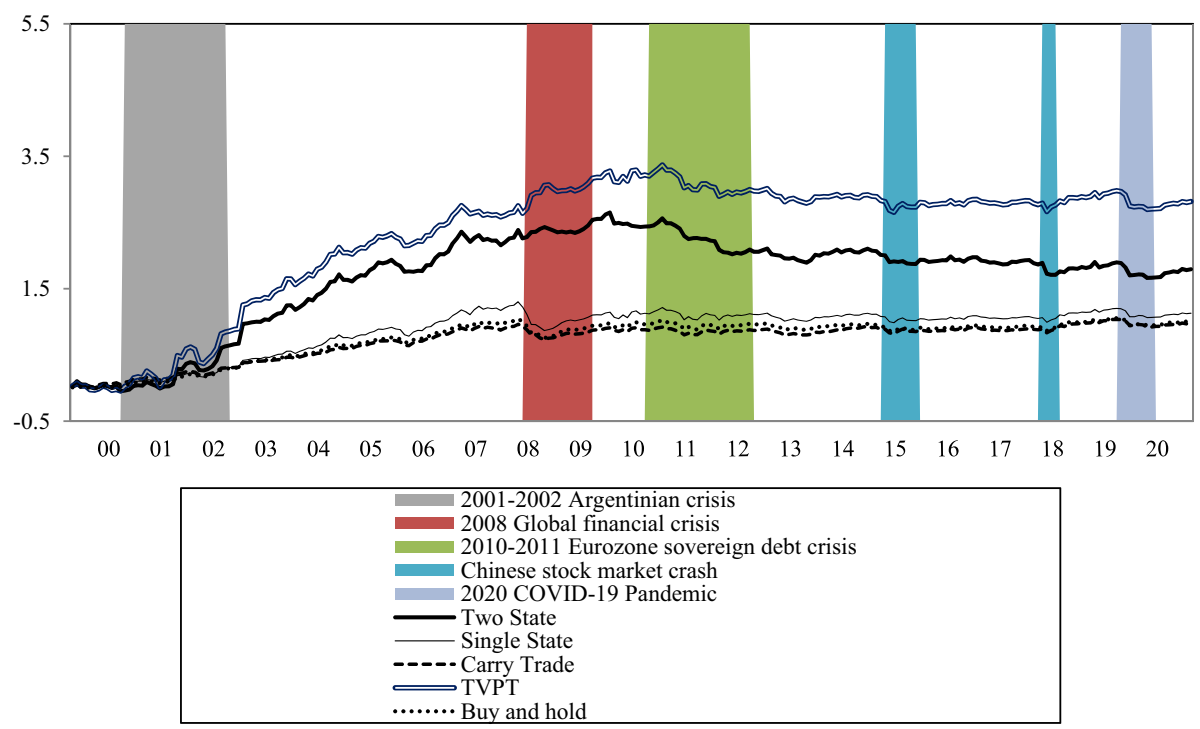

Fig. 6 Cumulative out of sample month-to-month returns for the two-state regime switching model (constant transition probabilities), the two-state regime switching model, with time-varying transition probabilities (TVTP), the single-state Gaussian IID model, a carry trade procedure as well as a buy and hold strategy $(\gamma=5)$

\section{Conclusion}

In this paper, we have adopted a Markov regime switching model for the joint distribution of returns on a portfolio that borrows in the US money market, whilst then investing in the foreign money one $(D O L)$ and a carry trade portfolio $\left(H M L_{F X}\right)$. We have found evidence of two economic regimes: one state capturing periods of low exchange rate volatility and high returns of both the $D O L$ and $H M L_{F X}$ portfolios. During this regime, low-interest 
rate currencies tend to depreciate, causing higher returns on the carry trade portfolio and UIP is violated. The other regime captures the periods of high FX volatility and negative return of the $H M L_{F X}$ portfolio. Moreover, the traditionally regarded safe-haven currency, the U.S. dollar, also appreciates during the high FX volatility state, according to the positive correlation between the $D O L$ and $H M L_{F X}$ portfolios. We have shown that this regime captures major currency crashes and periods, with a sustained declined in currency values, such as during the 1982 Latin American debt crisis, which lasted until 1991, the 1994 economic crisis in Mexico, the 1997 Asian financial crisis, the 1998 Russian financial crisis, the 1999 Brazilian currency crisis, the Argentinian crisis in 2001-2002, the 2008 global financial crisis, the 2010-2011 Eurozone sovereign debt crisis, the Chinese stock market crash in 2015-2016 and 2018, as well as the COVID-19 pandemic in 2020. In addition, the TED spreads are capable of predicting regime change through the time-varying transition probabilities.

To quantify the economic significance of regimes in returns on currency portfolios, we have further considered their importance in investors' optimal portfolio allocation problem. Strong short-term market timing effects have been found in optimal portfolio holdings across regimes in short investment horizons, while the optimal portfolio weights increasingly reflect horizon effects as the holding horizon grows. Rebalancing opportunities make investors respond more aggressively to the current state, because they can simply adjust the portfolio weight, if the perceived state probabilities change in the next period. We next compared the performance of the two-state RSM and a single state Gaussian IID model. The results show that, whilst the former generates high mean returns, it tends to be more volatile than the latter. Our findings also show that compared to the single-state Gaussian IID model and a carry trade as well as buy-and-hold strategy, our two-state model partially anticipates peso events as well as the changes of underlying related economic fundamentals, which strongly serves the overall performance of the portfolio.

Funding The Funding was provided by Ministry of Science and Technology, Taiwan, 102-2410-H-004 -063-, Chien-Hsiu Lin.

\section{References}

Ang A, Bekaert G (2002) International asset allocation with regime shifts. Rev Financ Stud 15:1137-1187

Barberis N (2000) Investing for the long run when returns are predictable. J Financ 55:225-264

Bazan-Palomino W, Winkelried D (2021) FX markets' reactions to COVID-19: are they different? Int Econ 167:50-58

Beck R, Rahbari E (2011) Optimal reserve composition in the presence of suddenstops. J Int Money Financ 30:1107-1127

Bergman UM, Hansson J (2005) Real exchange rates and switching regimes. J Int Money Financ $24: 121-138$

Bilson JFO (1981) The speculative efficiency hypothesis. J Bus 54:435-451

Brunnermeier MK, Nagel S, Pedersen LH (2009) Carry trades and currency crashes. NBER Macroecon Annu 23:313-347

Campbell J, Viceira L (1999) Consumption and portfolio decisions when expected returns are time varying. Rev Financ Stud 1:195-227

Caporale GM, Spagnolo N (2004) Modeling East Asian exchange rates: a Markov-switching approach. Appl Financ Econ 14:233-242

Christensen C, Ranaldo A, Söderlind P (2012) The time-varying systematic risk of carry trade strategies. J Financ Quant Anal 46:1107-1125 
Copeland L, Lu W (2016) Dodging the steamroller: fundamentals versus the carry trade. J Int Finan Mark Inst Money 42:115-131

Detemple J, Garcia R, Rindisbacher M (2003) A Monte Carlo method for optimal portfolios. J Financ 58:401-446

Diebold FX, Lee JH, Weinbach G (1994) Regime-switching with time-varying transition probabilities. In: Hargreves C (ed) Nonstationary time series analysis and cointegration. Oxford University Press, Oxford

Ding Z (2012) An implementation of markov regime switching model with time varying transition probabilities in matlab. Available at SSRN: https://ssrn.com/abstract=2083332

Doroodian K, Caporale T (2000) Currency risk and the safe-haven hypothesis. Atl Econ J 28:186-195

Engel C (1994) Can the Markov switching model forecast exchange rates? J Int Econ 36:151-165

Engel C, Hamilton J (1990) Long swings in the dollar: are they in the data and do markets know it? Am Econ Rev 80:689-713

Fleming J, Kirby C, Ostdiek B (2001) The economic value of volatility timing. J Financ 56:329-352

Fleming J, Kirby C, Ostdiek B (2003) The economic value of volatility timing using 'realized' volatility. J Financ Econ 67:473-509

Guidolin M, Timmermann A (2008) Size and value anomalies under regime shifts. J Financ Economet $6: 1-48$

Hamilton JD (1989) A new approach to the economic analysis of nonstationary time series and the business cycle. Econometrica 57:357-384

Hamilton JD (1994) Time series analysis. Princeton University Press, Princeton, NJ

Hansen LP, Hodrick R (1980) Forward exchange rates as optimal predictors of future spot rates: an econometric analysis. J Polit Econ 88:829-853

Ichiue H, Koyama K (2011) Regime switches in exchange rate volatility and uncovered interest rate parity. J Int Money Financ 30:1436-1450

Ismail MT, Isa Z (2007) Detecting regime shifts in Malaysian exchange rates. J Fundam Sci 3:211-224

Kirikos DG (2000) Forecasting exchange rates out of sample: random walk v.s Markov switching regimes. Appl Econ Lett 7:133-136

Lustig H, Roussanov N, Verdelhan A (2011) Common risk factors in currency markets. Revi Financ Stud 24:3731-3777

Manganelli S (2004) Asset allocation by variance sensitivity analysis. J Financ Econometrics 2:370-389

Merton RC (1971) Optimal consumption and portfolio rules in a continuous-time model. J Econ Theor 3:373-413

Patton A (2004) On the out-of-sample importance of skewness and asymmetric dependence for asset allocation. J Financ Econometrics 2:130-168

Samuelson PA (1969) Lifetime portfolio selection by dynamic stochastic programming. Rev Econ Stat 51:239-246

Timmermann A (2000) Moments of markov switching models. J Econometrics 96:75-111

West KD, Edison HJ, Cho D (1993) A utility-based comparison of some models of exchange rate volatility. $\mathrm{J}$ Int Econ 35:23-45

Wu C, Wu C (2017) The asymmetry in carry trade and the U.S. dollar. Q Rev Econ Financ 65:304-313

Publisher's Note Springer Nature remains neutral with regard to jurisdictional claims in published maps and institutional affiliations. 